\title{
Functional Outcome of Discectomy for Lumbar Disc Prolapse
}

\section{Ajit Swamy, Amit Swamy*, Kartikeya Sharma and Aniruddha Khirsagar}

Department of Orthopaedics, Dr. D. Y Patil Medical College, Hospital and Research centre, India

*Corresponding author: Department of Orthopaedics, Dr. D. Y Patil Medical College, Hospital and Research centre, India, Tel: 9766511189; E-mail: amit.swamy@gmail.com

Rec Date: July 24, 2017; Acc Date: August 08, 2017; Pub Date: August 13, 2017

Copyright: ( 2017 Swamy A, et al. This is an open-access article distributed under the terms of the Creative Commons Attribution License, which permits unrestricted use, distribution, and reproduction in any medium, provided the original author and source are credited.

\section{Abstract}

Background: This study was to find out that whether the lumbar disc prolapse at different level influence the functional outcome of patients after discectomy. Present study is of 50 adult cases admitted at D. Y Patil Medical College. Common age group involved was between $40-60$ years.

Aims: To assess whether there is any difference in functional outcome of patients with disc prolapse at different levels in the lumbar spine after performing discectomy

Objectives: To compare pre-operative and post-operative:

- Leg pain and back pain by Visual Analog Scale Score

- Functional outcome by Modified Oswestry Disability index score of the selected patients.

Materials and methods: This study was a comparative study, conducted for a period of about two years, July 2014 to September 2016 in dr. D. Y. Patil Medical College, Hospital \& Research Centre, only patients who were scrutinized for exclusion criteria and also abiding to inclusion criteria were included. Period required for data collection: 2 years. Period required for data analysis and reporting: - 6 months. We prospectively followed 50 consecutive patients with unilateral lumbar herniation either at L2-L3, L3-L4, L4-L5 or L5-S1 levels requiring surgery. The procedure performed was Micro lumbar discectomy in all patients.

Results: A total of 50 patients were included in our study of which 4 (8\%) patients had prolapsed intervertebral disc at L2-L3 level and $10(20 \%)$ patients had disc prolapsed at L3-L4 level. These 14 patients were included in upper lumbar level disc herniation group referred hereafter as Group 1 (28\%). 22 (44\%) patients had disc prolapsed at L4-L5 level and $14(28 \%)$ patients had disc prolapsed at L5-S1 level, these 36 patients were included in lower lumbar level disc herniation group who are referred hereafter as Group 2 (72\%).

On comparing the results after discectomy of prolapsed intervertebral disc at different levels in the lumbar spine we found no significant difference in the end result and functional outcome of the patients.

Conclusion: The aim of this study was to find out that whether the lumbar disc prolapse at different levels influence the functional outcome of patients. According to the observations of this study and after reviewing various similar studies done in the past we conclude that after discectomy, level of disc prolapse per se has no significant bearing on functional outcome of the patients.

Keywords: Disectomy; Lumbar disc; MRI imaging; Antibiotics

\section{Introduction}

Backache is one of the most common clinical symptoms encountered in medical practice. Low back pain is a symptom, not a disease. The pathologic basis for the pain may be something within the spine or a lesion outside of the spine [1] up to $80 \%$ of patients with acute low back pain, a precise anatomic cause cannot be localized. Typically, arrays of non-specific terms are used like lumbago, sprain, strain, mechanical low back pain and lumbar syndrome.

Prolapsed intervertebral disc is an important cause of spondylogenic backache. Although back pain is common from the second decade of life, intervertebral disc disease and disc herniation are most prominent in otherwise healthy people in third and fourth decades of life. Ninety five percent of lumbar disc herniation occurs at either L4-L5 or L5-S1 level [2].

The posterior longitudinal ligament affords only weak reenforcement especially at L4-L5 and L5- S1 level where it is a midline narrow unimportant structure attached to annulus [3].

The L4-L5 and L5-S1 articulations have the greatest motion in the lumbar spine. Greater motion causes an increased potential for instability, degeneration and breakdown and therefore the incidence of herniated discs is greater at L4-L5 and L5-S1 level than at any other lumbar disc space [4].

A Visual Analog Scale (VAS) [5] is a measurement instrument that tries to measure a characteristic or attitude that is believed to range across a continuum of values and cannot easily be directly measured. 
For example, the amount of pain that a patient feels ranges across a continuum from none to an extreme amount of pain.

The Modified Oswestry Disability Index (ODI) $[6,7]$ is an extremely important tool that researchers used to measure patient's functional disability due to low back pain. The test is considered as gold standard of low back functional outcome tools. The ODI is a valid and vigorous measure and has been a worthwhile outcome measure. It consists of questionnaire which has been designed to give us information as to know how the back pain has affected patient's ability to manage in everyday life. It categories the patient as having minimal, moderate or severe disability due to back pain.

\section{Materials and Methods}

This study is a comparative study was conducted for a period of about two years, July 2014 to September 2016 in Dr. D. Y. Patil Medical College, Hospital \& Research Centre. Only patients who were scrutinized for exclusion criteria and also abiding to inclusion criteria were included. Period required for data collection: 2 years. Period required for data analysis and reporting: 6 months. A study done by Murthy H, Reddy TVS showed a significant reduction in mean preop vas score from 7. 47 to 1.8016 with power of study $80 \%$ so We prospectively followed 50 consecutive patients with unilateral lumbar herniation at either L2-L3, L3-L4, L4-L5 or L5-S1 levels requiring surgery. All patients included in this study were operated by the same orthopaedic surgeon in the same operation theatre as the first case of the day. The procedure performed was Microlumbar discectomy in all patients [8]. Minimum follow up in this study was 2 months and maximum follow up was 20 months. Consecutive patients of either sex, in the age group 20yrs - 55yrs, who fulfilled the understated criteria, were operated. A total of fifty patients were selected with following inclusion criteria [3].

\section{Inclusion criteria}

- Patients over eighteen years old who had radicular pain for atleast four weeks with positive nerve root tension sign \& who had no relief after non-operative treatment like bed rest, analgesics, and traction for 4 weeks.

- Confirmatory cross-sectional MRI imaging study demonstrating intervertebral disc herniation at a level and side corresponding to their symptoms.

- Patients lying in ODI scoring group III were only included

- All patients who will have follow up of at least 3 months will be part of this study

Standard open fenestration and discectomy: Preoperative preparations: Patient was kept nil orally since the night prior to the day of operation. Entire back was prepared by shaving the part and thorough soap and water wash was given. Preoperative antibiotics were administered. Patient was induced by general anesthesia. The patient was placed prone in the knee-chest position. The abdomen was kept free, so as to keep the respiration free and prevent engorgement of the epidural veins and thus reduce bleeding (Figure 1).

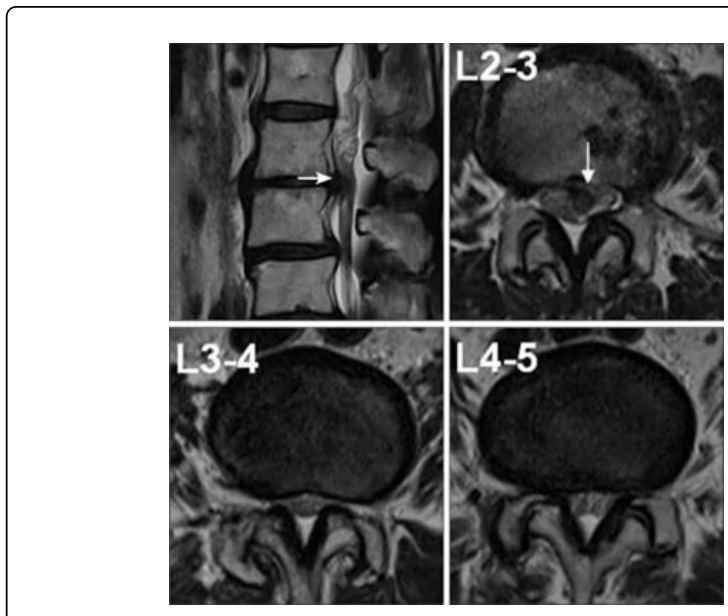

Figure 1: MRI showing disc prolapsed at various levels.

\section{Approach}

A mid-line vertical incision over the affected interspace of $8-10 \mathrm{~cm}$ is made after the back has been thoroughly painted and draped. The incision is deepened to the subcutaneous tissue and deep fascia. The lumbodorsal fascia is incised and the supraspinous ligament is incised over the affected disc space. By subperiosteal dissection, strip the paraspinal muscles from the spines and laminae of the vertebrae on each side and self-retaining retractors are applied. Using microscope partial laminectomy and discectomy was done using routine surgical technics (Figure 2).

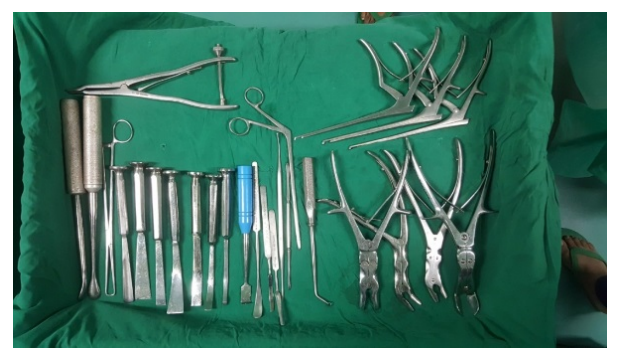

Figure 2: Instruments required for laminectomy and discectomy.

\section{After care}

Patient was allowed to turn in bed. Pain was controlled with injectable and oral NSAIDS. Postoperative antibiotic were administered. 24 hours post operatively patient was again examined for the severity of back pain and leg pain VAS score for this were noted (Figure 3). 
Page 3 of 7

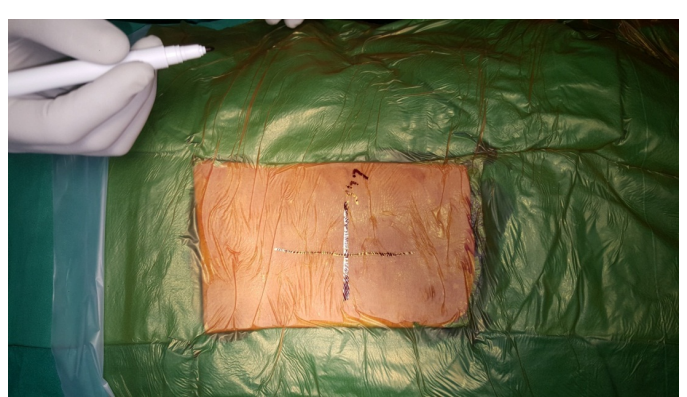

Figure 3: Preoperative draping.

Neurological function was closely monitored after surgery. Neurological function was monitored closely. For urinary retention patients were given antispasmodics and encouraged to pass urine. Catheterization was done if supportive measures failed. Sutures were removed after 10-12 days (Figure 4).

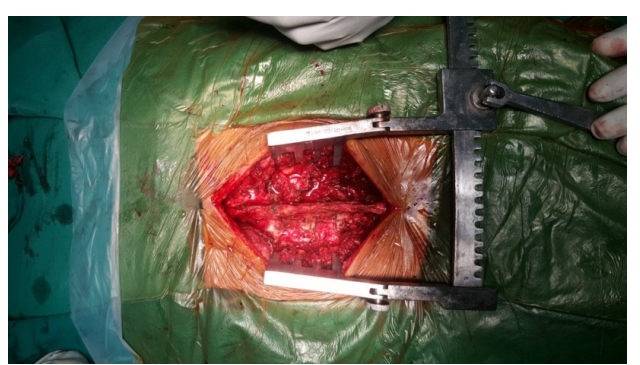

Figure 4: Exposure of lamina.

\section{Follow up evaluation}

- The leg and back pain analysis by VAS score was done 24 hours after surgery, then every week for 3 weeks, then at 1st month, 2nd months and finally at 3rd months on follow-up.

- The ODI was evaluated at 1 st month, 2 nd month and then at 3 rd months after the surgical procedure.

- These findings were compared between the groups for difference if any by statistical analysis.

\section{Results}

In our study patient data was recorded pre-operatively, $24 \mathrm{hrs}$ after surgery then on follow-up for every week for initial one month and then monthly for three months. Patients was called and evaluated on objective and subjective criteria, objectively, we use straight leg raising test [8], femoral stretch test [6] and Lasegue test. Subjectively we use visual analogue test, The Modified Oswestry Disability Index (ODI) [6,7] (Table 1).

\begin{tabular}{|l|l|l|l|}
\hline & Parameters & No of cases & Percentage (n=50) \\
\hline \multirow{2}{*}{ Lumber level } & Upper (Group I) & 14 & 28 \\
\cline { 2 - 4 } & Lower (Group II) & 36 & 72 \\
\hline \multirow{2}{*}{ Level } & L2 -L3 & 4 & 8 \\
\hline
\end{tabular}

\begin{tabular}{|l|l|l|l|}
\hline \multirow{4}{*}{} & L3-L4 & 10 & 20 \\
\cline { 2 - 4 } & L4 -L5 & 22 & 44 \\
\cline { 2 - 4 } & L5 -S1 & 14 & 28 \\
\hline \multirow{2}{*}{ Age (Yrs) } & $<40$ & 12 & 24 \\
\cline { 2 - 4 } & $>40$ & 38 & 76 \\
\hline \multirow{2}{*}{ Gender } & Male & 36 & 72 \\
\cline { 2 - 4 } & Female & 14 & 28 \\
\hline
\end{tabular}

Table 1: Level wise distribution of patients.

A total of 50 patients were included in our study of which $4(8 \%)$ patients had prolapsed intervertebral disc at L2-L3 level and 10 (20\%) patients had disc prolapsed at L3-L4 level. These 14 patients were included in upper lumbar level disc herniation group referred hereafter as Group 1 (28\%). 22 (44\%) patients had disc prolapsed at L4-L5 level and $14(28 \%)$ patients had disc prolapsed at L5-S1 level. These 36 patients were included in lower lumbar level disc herniation group who are referred hereafter as Group 2 (72\%) (Table 2).

\begin{tabular}{|l|l|l|l|l|l|}
\hline \multirow{2}{*}{ Parameter } & \multicolumn{2}{l|}{ Group I (n=14) } & \multicolumn{2}{l|}{ Group II (n=36) } & p-value \\
\cline { 2 - 6 } & Mean & SD & Mean & SD & \\
\hline Age (yrs) & 55.21 & 6.1 & 42.28 & 10.8 & $<0.001$ \\
\hline Gender (M:F) & $9: 5$ & & $27: 9$ & & 0.847 \\
\hline
\end{tabular}

Table 2: Comparison of age and gender in group I and group II.

Out of all the patients in the study a total of $36(72 \%)$ were males and $14(28 \%)$ were females. In Group 1 i.e., upper lumbar level patients, $9(64.29 \%)$ patients were male and $5(35.71 \%)$ patients were female. In group 2 i.e., lower lumbar level patients, 27 (75\%) were males and $9(5 \%)$ were females. By using 2 samples proportion tests, $\mathrm{p}$ value $>0.05$, therefore there is no significant difference between the proportion of gender in group 1 and group 2 (Table 3 ).

\begin{tabular}{|l|l|l|}
\hline Gender & Number of patients & Percentage (\%) \\
\hline Male & 36 & 72 \\
\hline Female & 14 & 28 \\
\hline Total & 50 & 100.00 \\
\hline
\end{tabular}

Table 3: Gender wise distribution of patients.

\begin{tabular}{|c|c|c|c|c|}
\hline \multirow[t]{2}{*}{ Group } & \multicolumn{2}{|l|}{ Gender } & \multirow[t]{2}{*}{ Total } & \multirow[t]{2}{*}{ p-value } \\
\hline & Male & Female & & \\
\hline Group 1 & $9(64.29 \%)$ & $5(35.71 \%)$ & 14 & \multirow[t]{2}{*}{0.847} \\
\hline Group 2 & $27(75.0 \%)$ & $9(25.0 \%)$ & 36 & \\
\hline
\end{tabular}

Table 4: Gender wise distribution of patients in our study group.

The mean age of patients in the group 1 was 55.21 years $(\mathrm{SD}= \pm$ 6.10) with a minimum age of 48 and a maximum age of 70 while in the group 2 , mean age being 42.28 years $(S D= \pm 10.80)$ with minimum age 
of 20 and a maximum of 59 . By using 2 independent sample t-test, $\mathrm{p}$ value $<0.05$, therefore there is significant difference between group 1 and group 2 patients with respect to age (years) (Table 4 ).

The maximum number of patients i.e., 8 in group 1 are in 51-60 yrs age group while in group 2, 18 patients are in 41-50 yrs age group. Thus, we conclude that upper lumbar level disc herniation is more common in elderly age group while lower lumbar level disc prolapse is more common in middle age group (Table 5).

\begin{tabular}{|l|l|l|}
\hline \multirow{2}{*}{ Age group } & Number of patients \\
\cline { 2 - 3 } & Group 1 & Group 2 \\
\hline$<20$ & 0 & 2 \\
\hline $21-30$ & 0 & 4 \\
\hline $31-40$ & 0 & 6 \\
\hline $41-50$ & 4 & 18 \\
\hline $51-60$ & 8 & 6 \\
\hline $61-70$ & 2 & 0 \\
\hline Total & 14 & 36 \\
\hline
\end{tabular}

Table 5: Age wise distribution in Group 1 and 2.

Visual analog scale was used to quantify leg pain and back pain. The mean VAS score for leg pain in the group 1 in the pre-operative period was $9.40(\mathrm{SD}= \pm 0.87)$ with $1(7.14 \%)$ patient having minimum score of 7 and $4(28.57 \%)$ patients had maximum score of 10 . In group 2 the mean pre-operative VAS score for leg pain was $9.44(\mathrm{SD}= \pm 0.88)$ with $2(5.55 \%)$ patients having a minimum value of 7 and $23(63.88 \%)$ patients had maximum value of 10 . There was no significant difference ( $p$-value $=0.121)$ in preoperative VAS scores for le pain in group 1 and group 2 (Table 6).

\begin{tabular}{|l|l|l|l|}
\hline Group & Number of patients & Age (Mean + SD) & p-value \\
\hline Group 1 & 14 & $55.21+6.10$ & $<0.001$ \\
\hline Group 2 & 36 & $42.28+10.80$ & \\
\hline
\end{tabular}

Table 6: Comparision of age (years) in group 1 and group 2.

At $24 \mathrm{hrs}$ post-operatively the mean leg pain in the group 1 was reduced to $2.79(\mathrm{SD}= \pm 0.69)$ with $5(35.71 \%)$ patients having minimum of 2 and a maximum score of 4 was noted in 2 patients (14.28\%) whereas in the group 2 the mean score was reduced to 2. 89 $(\mathrm{SD}= \pm 1.56)$ with a minimum score of 1 found in $8(22.22 \%)$ patients and a maximum score of 7 was recorded in $1(2.77 \%)$ patient. The difference in VAS scores for pain at $24 \mathrm{hrs}$ post-operatively between group 1 and 2 was not significant ( $\mathrm{p}$-value $=0.749$ ).

On follow at one week the mean leg pain was $0.71(\mathrm{SD} \pm 0.61)$ with $5(35.71 \%)$ patients had no pain (VAS=0) and single patient $(7.14 \%)$ had maximum score 2 in group 1 whereas in the group 2 mean score for leg pain was $0.81(\mathrm{SD}= \pm 0.89)$ with no pain in $15(41.66 \%)$ patients $(\mathrm{VAS}=0)$ and a maximum score of 4 was found in single patient $(2.77 \%)$. The difference in VAS scores for pain at one week follow up between group 1 and 2 was not significant ( $\mathrm{p}$-value $=0.682$ ).
However, at two weeks follow up the mean leg pain was 0.43 $(\mathrm{SD}=0.51)$ in the group 1 while in the group 2 mean leg pain was 0.11 $(\mathrm{SD}=0.40)$. At three weeks follow- up only two patients in group 1 had leg pain while in group 2 no patient reported leg pain. On further follow up all patients in both groups reported no leg pain.

By using 2 independent sample t-test $\mathrm{p}$-value $>0.05$, pre-operatively, $24 \mathrm{hr}$ post-operative, at 1 st week to $3 \mathrm{rd}$ month. Therefore, we conclude that there is no significant difference between the mean VAS score for leg pain pre-operatively, $24 \mathrm{hrs}$ post-operatively, at $1^{\text {st }}$ week, $2^{\text {nd }}$ week, $3^{\text {rd }}$ weeks, $1^{\text {st }}$ month, $2^{\text {nd }}$ month and $3^{\text {rd }}$ month follow-up in group 1 and group 2 (Table 7 ).

\begin{tabular}{|l|l|l|l|l|l|}
\hline \multirow{2}{*}{ VAS for leg pain } & \multicolumn{2}{l|}{ Group I (n=14) } & \multicolumn{2}{l|}{ Group II (n=36) } & p-value \\
\cline { 2 - 6 } & Mean & SD & Mean & SD & \\
\hline Pre-operative & 9.4 & 0.87 & 9.44 & 0.88 & 0.121 \\
\hline At 24 hrs & 2.79 & 0.69 & 2.89 & 1.56 & 0.749 \\
\hline At 1st wee & 0.71 & 0.61 & 0.81 & 0.89 & 0.682 \\
\hline At 2nd week & 0.43 & 0.51 & 0.11 & 0.4 & 0.051 \\
\hline At 3rd week & 0.14 & 0.36 & 0 & 0 & 0.165 \\
\hline At 1 month & 0 & 0 & 0 & 0 & 1 \\
\hline At 2 months & 0 & 0 & 0 & 0 & 1 \\
\hline At 3 months & 0 & 0 & 0 & 0 & 1 \\
\hline
\end{tabular}

Table 7: Comparison of VAS score for leg pain in group 1 and group 2.

The mean VAS score for back pain in group 1 in the pre-operative period was $6.57(\mathrm{SD} \pm 1.22)$ with $3(21.42 \%)$ patient having a minimum score of 5 and a maximum of 9 was noted in $1(7.14 \%)$ patient. In the group 2 the mean pre-operative VAS score for back pain was $4.52(\mathrm{SD}= \pm 1.57)$ with $1(2.77 \%)$ patient having a minimum value of 1 and $2(5.14 \%)$ with maximum of 8 . There is significant difference (p-value $=0.019)$ in preoperative VAS scores for back pain in group $1 \&$ group 2.

\begin{tabular}{|l|l|l|l|l|l|}
\hline \multirow{2}{*}{ VAS for leg pain } & \multicolumn{2}{l|}{ Group I (n=14) } & \multicolumn{2}{l|}{ Group II (n=36) } & p-value \\
\cline { 2 - 6 } & Mean & SD & Mean & SD & \\
\hline Pre-operative & 6.57 & 1.22 & 4.52 & 1.57 & 0.019 \\
\hline At 24 Hrs & 2.29 & 0.99 & 1.58 & 1.59 & 0.008 \\
\hline At 1st week & 0.86 & 0.95 & 0.44 & 0.9 & 0.554 \\
\hline At 2nd weeks & 0.36 & 0.63 & 0.17 & 0.74 & 0.756 \\
\hline At 3rd weeks & 0.29 & 0.61 & 0.06 & 0.33 & 0.843 \\
\hline At 1 month & 0.57 & 0.85 & 0.06 & 0.33 & 0.843 \\
\hline At 2 months & 0.29 & 0.61 & 0 & 0 & 0.325 \\
\hline At 3 months & 0.29 & 0.61 & 0 & 0 & 0.325 \\
\hline
\end{tabular}

Table 8: Comparison of VAS scores for back pain in group 1 and 2.

24 hours post-operatively mean back pain was $2.29(\mathrm{SD}= \pm 0.99)$ in the group 1 with a minimum score of 1 noted in $3(21.42 \%)$ patients and a maximum of 4 in two patients (14.28\%). In group 2 the mean 
Page 5 of 7

back pain 24 hours after surgery was $1.58(\mathrm{SD}= \pm 1.59)$ with minimum score of 0 noted in 12 (33.33\%) patients and a maximum of 5 in 2 (5.55\%). There Was significant difference ( $\mathrm{p}$-value $=9.008)$ in postoperative 24 hours VAS scores for back pain in group I and group 2 (Table 8).

On follow at one week the mean leg pain was $0.86(\mathrm{SD}= \pm 0.95)$ with a minimum score of 0 noted in 7 (50\%) patients and a maximum of 5 noted in $2(14.28 \%)$ patients in group 1 while in the group 2 mean VAS score was $0.44(\mathrm{SD} \pm 0.90)$ with a minimum of 0 noted in $26(72.26 \%)$ patients and a maximum score of 4 in $1(2.77 \%)$ patient. The difference in VAS scores for back pain at one week follow up between group 1 and group 2 was NOT significant ( $\mathrm{p}$-value $=0.554$ ).

However, at two weeks follow up the mean back pain was 0.36 $(\mathrm{SD}=0.63)$ in the group 1 while in the group 2 mean was 0.17 $(\mathrm{SD}=0.74)$. On further follow up patients in group 1 had some back pain while patients in group 2 had no back pain except for one patient who had complication of wound infection.

By using 2 independent sample t-test, $\mathrm{p}$-value $<0.05$ pre-operatively and 24 hrs post-operatively but $\mathrm{p}$-value $>0.05$, at follow up from $1^{\text {st }}$ week to $3^{\text {rd }}$ month post operatively. Therefore, we can conclude that there is no significant difference between the mean VAS score for back pain at $1^{\text {st }}$ week, $2^{\text {nd }}$ week, $3^{\text {rd }}$ week, $1^{\text {st }}$ month, $2^{\text {nd }}$ month and $3^{\text {rd }}$ month in group 1 and group 2 though there is significant difference preoperatively and initially post-operatively at $24 \mathrm{hrs}$. Back pain was more significant in upper lumbar disc prolapses (Table 9).

\begin{tabular}{|l|l|l|l|l|l|}
\hline \multirow{2}{*}{ Oswesty score } & \multicolumn{2}{|l|}{ Group I (n=14) } & \multicolumn{2}{l|}{ Group II (n=36) } & \multirow{2}{*}{ p-value } \\
\cline { 2 - 6 } & Mean & SD & Mean & SD & \\
\hline Pre-operative & 52.29 & 4.76 & 50.28 & 6.01 & 0.225 \\
\hline Post op 1st month & 10.43 & 1.95 & 20.94 & 3.15 & $<0.0001$ \\
\hline Post op 2nd month & 6.71 & 2.01 & 12.11 & 3.54 & $<0.0001$ \\
\hline Post op 3rd month & 5.43 & 1.45 & 6.28 & 1.53 & 0.079 \\
\hline
\end{tabular}

Table 9: Comparison of Oswesty score in group 1 and 2.

We used modified Oswestry Disability questionnaire and calculated the Oswestry Disability Index pre-operatively and at follow-ups at $1^{\text {st }}$ month, $2^{\text {nd }}$ months and $3^{\text {rd }}$ months post-operatively to evaluate the functional outcome of patients. The pre-operative mean ODI in-group 1 was 52.29 ( $\mathrm{SD} \pm 4.76)$ while that in-group 2 was $50.28(\mathrm{SD}= \pm 6.01)$. However, there was no significant difference ( $p$-value $=0.225$ ) in the pre-operative ODI in the two groups.

The mean ODI in group 1 reduced to $10.43(\mathrm{SD} \pm 1.95)$ at 1 month follow up while that in group 2, the mean ODI reduced to 20. $94(\mathrm{SD}=$ \pm 3.15 ) while at second month follow-up the mean ODI in group 1 was 6. $71(\mathrm{SD}=2.01)$ and 12. $11(\mathrm{SD}= \pm 3.54)$ in group 2. This difference in the ODI scores between the two groups was significant ( $\mathrm{p}$ value $<0.001$ ).

At 3 rd month of follow up the mean ODI in group 1 reduced to 5 . $43(\mathrm{SD}= \pm 1.45)$ while that in group 2 reduced further to $6.28(\mathrm{SD}= \pm$ 1.53). This difference in the ODI scores between the two groups was NOT significant at third month of follow up (p-value=0.079).

By using 2 independent sample t-test p-value $>0.05$ therefore we conclude that there is no significant difference between the mean Oswestry score at pre-operatively and at 3rd month follow-up in group 1st and group 2nd but initially at 1st month and 2nd month follow up there is significant difference in Oswestry scoring in two groups.

Patients with upper or higher lumbar level lesions improved significantly initially after discectomy with better functional outcome but on long term follow up functional outcomes in both groups after discectomy were same.

All patients in both groups, as a protocol, were discharged on the 5 th postoperative day. Only one patient in-group 2 had complication of wound infection. No other complications were noted. All patients by the end of follow up ( $3^{\text {rd }}$ month) had returned to their original job.

\section{Discussion}

We prospectively followed 50 consecutive patients with unilateral lumbar herniation at L2-L3, L3-L4, L4-L5 or L5-S1 levels after discectomy.

\section{Level of disc prolapse}

A total of 50 patients which were included in our study of which only $4(8 \%)$ patients had disc prolapse at L2-L3 level while $10(20 \%)$ patients had disc prolapse at L3-L4 level who are referred as Group 1. L2-L3 and L3-L4 levels constitutes so called upper lumbar disc herniation group. $22(44 \%)$ patients had prolapsed intervertebral disc at L4-L5 level and 14 (28\%) at L5-S1 level, who are referred as Group 2 [9]. L4-L5 and L5-S1 levels constitutes so called lower lumbar disc herniation group. Thus, most common level of disc prolapse in our study is L4-L5 level followed by L5-S1 level which together forms $72 \%$ of our patients. According to literature, the majority of lumbar herniation occurs at the L4-L5 and L5-S1 intervertebral disc levels, affect the L5 and S1 roots, and result in sciatica. Upper level herniation (levels L2-L3 or L3-L4) are less common, may affect the L2, L3, and L4 nerve roots and cause a femoral radiculopathy [10-13].

\section{Sex distribution}

Out of all the patients in the study a total of $36(72 \%)$ were males and $14(28 \%)$ were females. In Group 1 that is upper lumbar level patients, $9(64.29 \%)$ patients were male and $5(35.71 \%)$ patients were female. In group 2 that is lower lumbar level patients, 27 (75\%) were males and $9(25 \%)$ were females. By using 2 samples proportion test pvalue $>0.05$ therefore there was no significant difference between the proportion of gender in group 1 and group 2 in our study. But disc problem was more preponderant in males than females. Similarly, in the study acne by Lurie and et al., the majority of the study population (57\%) was male [14]. Also in study done by Saberi et al., male to female ratio was 1.08 and 1.14 in the upper and lower lumbar disc herniation, respectively [15].

\section{Age significance}

The mean age of patients in the group 1 was 55.21 years $(\mathrm{SD} \pm 6.10)$ with a minimum age of 48 and a maximum age of 70 while in the group 2 , mean age being 42.28 years $(S D= \pm 10.80)$ with minimum age of 20 and a maximum of 59. By using 2 independent sample t-test pvalues $<0.05$, therefore there was significant difference between group 1 and group 2 patients with respect to age (years). The maximum number of patients i.e., 8 in group 1 were in 51-60 years of age while in group 2, 18 patients were in 41-50 years age group. Thus, we conclude that upper lumbar level disc herniation was more common in elderly age group while lower lumbar level disc prolapse was more common in 
middle age group, In the study done by hooshang Saberi et al., The mean age of patients with upper lumbar disc herniation and lower lumbar disc herniation were 45.7 years (23-70) and 41.2 years (20-63), respectively 43. Similarly, in SPORT trial by Lurie et al. case study the level of herniation varied directly with age, as patients with upper level herniation were significantly older, the L4-L5 group was of an intermediate age, and the L5-S1 group was the youngest [14].

\section{Pain analyses}

The severity of the leg pain and back pain was noted by the VAS score. The pre-operative VAS scores were more for leg pain than back pain in both groups. Patients in both groups had more leg pain than back pain. Patients in group 1 with upper lumbar level disc prolapse had more back pain as compared to patients in group 2 with lower lumbar level disc prolapse.

\section{Leg pain:}

1. Pre-operative leg pain in group 1 (mean VAS=9.4) was not significantly different $(\mathrm{p}$-value $=0.12)$ from the leg pain in group 2 (mean VAS=9.44). There was an initial rapid decrease in the leg pain scores in both groups from 9.4 in the pre-operative period to 2.79 and 2.89 respectively $24 \mathrm{hrs}$ after operation. This rapid decrease in leg pain scores is similar in both groups (pvalue $=0.74$ ).

2. On follow at one week the mean leg pain was $0.71(\mathrm{SD}= \pm 0.61)$ with $5(35.71 \%)$ patients had no pain $(\mathrm{VAS}=0)$ in group 1 whereas in the group 2 mean score for leg pain was $0.81(\mathrm{SD}= \pm$ 0.89 ) with no pain in $15(41.66 \%)$ patients (VAS $=0)$. The difference in VAS scores for pain at one week follow up between group 1 and 2 was not significant ( $\mathrm{p}$-value $=0.682$ ).

3. However, at two weeks follow up the mean leg pain was 0.43 $(\mathrm{SD}=0.51)$ in the group 1st while in the group 2nd mean leg pain was $0.11(\mathrm{SD}=0.40)$. At three weeks follow-up only two patients in group 1 had leg pain while in group 2 no patient reported leg pain, on further follow up all patients in both groups reported no leg pain.

4. There was no significant difference between the mean VAS score for leg pain preoperatively, 24 hours post-operatively, at $1^{\text {st }}$ week, $2^{\text {nd }}$ week, $3^{\text {rd }}$ week, $1^{\text {st }}$ month, $2^{\text {nd }}$ month and $3^{\text {rd }}$ month of follow-up in group 1 and group 2.

\section{Back pain:}

1. The pre-operative back pain scores were 6.57 in group 1 and 4.52 in group 2. Scores reduced to 2.29 in group 1 and 1.58 in group 2 $24 \mathrm{hrs}$ post-operatively. There was a. statistically significant difference $(p$-value $=0.019$ and 0.008$)$ in the VAS scores for back pain pre-operatively and $24 \mathrm{hrs}$ post-operatively: Patients with upper lumbar level disc prolapse had more back pain than patients with lower lumbar disc prolapse pre-operatively and at initial follow-up at $24 \mathrm{hrs}$ post-operatively.

2. On follow at one week the mean back pain was $0.86(\mathrm{SD}= \pm 0.95)$ in group 1 while in the group 2 mean VAS score was 0.44 ( $\mathrm{SD}= \pm$ $0.90)$. The difference in VAS scores for back pain at one week follow up between group 1 and group 2 was NOT significant ( $\mathrm{p}$ value $=0.554)$. However, at two weeks follow up the mean back pain was $0.36(\mathrm{SD}=0.63)$ in the group 1 while in the group 2 mean was $0.17(\mathrm{SD}=\mathrm{O} .74)$. On further follow up patient's ingroup 1 had some residual mild back pain while patients in group 2 had no back pain except for one patient who had complication of wound infection.
3. There was no significant difference between the mean VAS score for back pain at $1^{\text {st }}$ week, $2^{\text {nd }}$ week, $3^{\text {rd }}$ week, $1^{\text {st }}$ month, $2^{\text {nd }}$ month and $3^{\text {rd }}$ month at follow-up in group 1 and group 2 though there is significant difference pre-operatively and initially postoperatively at 24 hours. Back pain was more significant in upper lumbar disc prolapses. (Table 8).

According to Adam Pearson and et al., Surgery resulted in greater improvement in both back ache, leg pain than non-operative treatment at each follow-up period; however, leg pain improved significantly more than back pain. The treatment effect of surgery was greater for leg pain than back pain at 3 months but not at 1 or 2 years.

\section{Functional status}

The disability due to prolapsed intervertebral disc was assessed using the Modified Oswestry Disability Index (MODI) determined before surgical procedure then at $1^{\text {st }}$ month, $2^{\text {nd }}$ month and then at $3^{\text {rd }}$ month after the surgical procedure. The mean ODI in pre-operative period was 52.29 for group 1 and 50.28 for group 2. At $1^{\text {st }}$ month follow up ODI in group 1 reduced to $10.43,6.71$ at $2^{\text {nd }}$ month and then to 5.43 at $3^{\text {rd }}$ month whereas in group 2 it was 20.94 at $1^{\text {st }}$ month, 12.11 at $2^{\text {nd }}$ month and 6.28 at $3^{\text {rd }}$ month. Thus, initially patients with upper lumbar level disc prolapse showed less disability and better function after discectomy as compared to patients with lower lumbar level disc prolapse but at the end of three months there was no significant difference in the functional outcome in both the groups of patients [16].

Similar to our results J. Lurie and et al. found that the relative advantage for surgery was greater for patients with herniation at higher lumbar levels, with non- operative treatment being less effective in these patients compared with those with herniation at L4-L5 and L5S1 levels. In contrast, Sanderson et al. reported that patients with L1-L2 or L2-L3 discectomy had significantly worse surgical outcome than the ones with L3-L4, L4-L5 and L5-S1 discectomies. The extent of improvement in radicular pain, back pain and function and economic status were found to be $58 \%, 53 \%$ and $33 \%$, respectively in his study. On the other hand, the surgical outcome in the L3-L4 group was favorable and similar to L4-L5 and L5-S1 group. The reason for this might be that most of their patients with L1-L2 and L2-L3 disc herniation in his study had previous lumbar disc surgeries [17].

However, the improvement in the functional disability of the patients was similar in both the groups of patients in long term followup in our study. This again ascertains the fact that level of herniation has no significant bearing on the functional outcome of the patient in long term if proper decompression has been achieved by discectomy. Mechanical factors do not influence the functional outcome in patients with prolapsed disc after discectomy.

\section{Conclusion}

We also found that upper lumbar disc herniation was more common in elderly adults above 50 years of age while lower lumbar disc prolapse was more common in middle age group 40 to 50 years.

- The relative advantage for surgery was greater for patients with herniation at higher lumbar levels initially compared with those with herniation at L4-L5 and L5-S1 levels.

- Mechanical factors like level of disc herniation do not influence the functional outcome in patients with prolapsed lumbar disc after discectomy. 
Citation: Swamy A, Swamy A, Sharma K, Khirsagar A (2017) Functional Outcome of Discectomy for Lumbar Disc Prolapse. J Spine 6: 382. doi: $10.4172 / 2165-7939.1000382$

Page 7 of 7

- On comparing the results after discectomy of prolapsed intervertebral disc at different levels in the lumbar spine we found no significant difference in the end result and functional outcome of the patients.

\section{References}

1. Deyo RA, Rainville J, Kent DL (1992) What can the history and physical examination tell us about low back pain? JAMA 268: 760-765.

2. Williams KD, Park AL (2008) Lower back pain and disorders of intervertebral disc In: S. Terry Canale, James H Beaty, (eds). Campbell's Operative Orthopaedics: Mosby Elsevier, Phiiadelphia, USA. pp: 17-29.

3. Wong DA, Transfeldt E (2007) Macnab’s backache. Lippincott Williams \& Wilkins, Philadelphia, USA. pp: 2-3.

4. Hoppenfeld S, Hutton R (1997) Orthopaedic neurology; Lippincott Williams and Wilkins, Philadelphia, USA. pp: 66.

5. Price DD, McGrath PA, Rafii A, Buckingham B (1983) The validation of visual analogue scales as ratio scale measures for chronic and experimental pain. Pain 17: 45-56.

6. Vianin M (208) Psychometric properties and clinical usefulness of the Oswestry Disaility lnd. J Chiropr Med 7: 161-163.

7. Mixter WJ, Barr JS (1934) Rupture of intervertebral disc with involvement of spinal canal. N Engl J Med 211: 10-215.

8. Williams KD, Park AL (2008) Lower back pain and disorders of intervertebral disc In: S. Terry Canale, James H Beaty, (eds). Campbell's Operative Orthopaedics Mosby Elsevier, Philadelphia, USA. pp: 1729.
9. Xin SQ, Zhang QZ, Fan DH (1987) Significance of straight-leg raising test in the diagnosis and clinical evaluation of lower lumbar intervertebraldisc protrusion. J Bone Joint Surg Am 69: 517-522.

10. Anderson GJ (1997) The epidemiology of spinal disorders. In: Frymoyer JW, editor. The adult spine: Principles and practice. 2nd edn. LippincottRaven, Philadelphia, USA. pp: 127.

11. Dammers R, Koehler PJ (2002) Lumbar disc herniation: Level increases with age. Surg Neurol 58: 209-213.

12. Hsu K, Zucherman J, Shea W, Kaiser J, White A, et al. (1990) High lumbar disc degeneration. Incidence and Etiology. Spine 15: 679-682.

13. Hijikata S (1989) Pecutanous nucleotomy. A new concept technique and 12 years' experience. Clin Orthop Relat Res 238: 9-23.

14. Spangfort EV (1972) The lumbar dic herniation. A computer-aided analysis of 2,504 operations. Acta Orthop Scand Suppi 142: 1-95.

15. Lurie JD, Faucett SC, Hanscom B, Tosteson TD, Ball PA, et al. (2008) Lumbar discectomy outcomes vary by herniation level in the spine patient outcomes research trial. J Bone Joint Surg Am 90: 1811-1819.

16. Saberi H, Isfahani AV (2008) Higher preopeative Oswestry Disability Index is associated with better surgical outcome in upper lumbar disc herniations. Eur Spine J 17: 117-121.

17. Murthy H, Reddy TVS (2016) VAS score assessment for outcome of posterior lumbar inter body fusion in cases of lumbar canal stenosis. Int J Res Orthop 2: 164-169. 